\title{
Measure Noun constructions: An instance of semantically-driven grammaticalization
}

\author{
Lieselotte Brems \\ University of Leuven
}

In a narrow sense, the term 'Measure Noun' (MN) refers to such nouns as acre and kilo, which typically measure off a well-established and specific portion of the mass or entity specified in a following of-phrase, e.g. a kilo of apples. When used like this, the $\mathrm{MN}$ is generally considered to constitute the lexical head of the bi-nominal noun phrase. However, the notion of 'MN' can be extended to include such expressions as a bunch of and heaps of, which, strictly speaking, do not designate a 'measure', but display a more nebulous potential for quantification.

The structural status of MNs in this broader sense then is far from straightforward and most grammatical reference works of English are either hesitant or silent with regard to the issue. Two main analytical options seem to suggest themselves. Either the $\mathrm{MN}$ is interpreted as constituting the head of the NP, with the of -phrase as a qualifier to this head, or the MN is analysed as a modifier, more specifically a quantifier, to the head, which in this case is the noun in the of -phrase.

Starting from the structural analyses of MN-constructions offered by such linguists as Halliday and Langacker, my paper goes on to discuss a corpus study aimed at charting and elucidating the structural ambivalence observed in MN-constructions. The framework eventually opted for is that of 'grammaticalization', since it provides the most comprehensive account for the developments displayed by MN-constructions, in that it brings to the fore the very intricate interplay between the lexical and the grammatical status of the MN. In addition, it also does justice to the diachronic dimension implied in the mechanisms of delexicalization and grammaticalization.

Keywords: grammaticalization, delexicalization, emergent quantifiers, quantitative profiles, vagueness 


\section{Introduction to $\mathrm{MN}$-constructions: What's in a name ${ }^{1}$}

'Measure Nouns' (henceforth MNs) or 'nouns of measurement ${ }^{2}$ in the strict sense are nouns such as acre, litre, pound, ounce, etc. that measure off a welldefined standard-like portion of the mass or entities specified in the of -phrase following the $\mathrm{MN}$, as in an acre of wasteland.

However, this paper extends the use of the term $\mathrm{MN}$ to include nouns which, strictly speaking, do not designate a 'measure', but display a more nebulous potential for quantification. More specifically, the $\mathrm{MN}$-expressions in this broader sense which I will study in this article are a bunch of, bunches of, a heap of, heaps of, a pile of and piles of. The type of construction in which they are used is a bi-nominal noun phrase of the kind illustrated in the following set of examples:

(1) The fox, unable to reach a bunch of grapes that hangs too high, decides that they were sour anyway. (CB)

(2) A jilted girlfriend got revenge on the boyfriend who dumped her by dumping a foot-high pile of manure in his bed. (CB)

(3) We still have to move loads of furniture and other stuff.

(4) The 'surrogate mum' to princes William and Harry shared heaps of fun with them at a fair yesterday while father Charles was otherwise engaged.(CB)

(5) I would take up a pile of commonplace books like Lord David Cecil's Library Looking Glass, John Julius Norwich's Christmas Crackers, Rupert Hart-Davis's A Beggar in Purple, etc.(CB)

(6) Then I noticed, under a pile of other books on my nightstand, the worn journal my father had given me those weeks ago. $(\mathrm{CB})^{3}$

The central question that I will be concerned with in this article is: what is the status of the MNs bunch, pile, loads and heaps within their respective NPs? Does the MN constitute the head noun, or does it function as a quantifier to the head noun in the of-phrase $(=\mathrm{N} 2)$ ? I will also investigate to what extent the status of the MN within the nominal construction has repercussions at clause level, most notably on the question of subject-verb concord whenever the MN-nominal occurs in subject position.

There is a considerable gap in the existing literature with regard to $\mathrm{MN}$ constructions. Both traditional pedagogic grammars and more theoretical accounts treat them with remarkable vagueness and even imprecision. Quirk et 
al. ( 1972 and 1985), Kruisinga (1925); Jespersen (1970) and Biber et al. (1999) for example all offer a rather disparate account of MNs, mainly restricted to discussing them as MNs in the narrow sense. MNs are typically mentioned in sections on types of concord, in which the observed fluctuation in verb agreement serves as an example of conflicting principles of verb agreement. With regard to this matter most grammars consider the MN to be the head without much further question. Hence, in those cases where the verb agrees in number with the grammatical number of the $\mathrm{MN}$, grammatical concord is said to be satisfied. If it agrees with the second noun, this incongruence is explained as notional concord overruling strict grammatical concord. Alternatively, the principle of proximity concord or attraction is invoked, which means that whatever noun or pronoun most closely precedes the finite verb controls the number of the verb. The possibility of N2 actually constituting the head in at least some cases is not really considered. The status of the MN and N2 is not systematically questioned and whenever it seems to come up for discussion, only straightforward examples are used. (Jespersen 1970: 179; Kruisinga 1925:306; Quirk et al. 1972:365-367, 1985:264; Biber et al. 1999:184-185).

Neither is the specific quantifying function of MNs ever explained in much detail; comments are limited to recognizing $\mathrm{MNs}$ as an incongruent means of 'countizing' uncountables, referred to as "individuation" or "individualization” (Kruisinga 1925:33; Jespersen 1970:117; Quirk et al. 1985:249; Biber et al. 1999:252). Finally, most grammars also mention that MN-expressions are typically associated with informal registers (see below). In sum, the existing literature seems somewhat at a loss with regard to MNs. They are perceived as slipping through the system in a rather unpredictable way and hence receive an unsystematic and ad hoc treatment, as with the conflicting principles of subject-verb concord.

Yet, the existing literature seems aware that $\mathrm{MN}$-constructions are very much grammar 'in movement'. In this article I will make the point that the logical beginning and end points of this development, as well as the stages in between, have to be treated with precision. I will also argue that the most adequate way of making order out of the perceived chaos is by bringing in the perspective of grammaticalization (cf. Lehmann 1985: Hopper \& Traugott 1993). I will argue more extensively for this approach in Section 2.3.

Let us first run through the above set of examples in order to acquire a first impression of the specific rub of $\mathrm{MN}$-constructions. Sentence (1) is rather unproblematic, in that it displays the collocationally restricted meaning and use of bunch which designates a very specific constellation onto the entities 
or mass specified in the of-phrase following the MN. The New Shorter Oxford English Dictionary (Brown 1993) provides the following definition of bunch: "A cluster of things growing or fastened together". Bunch refers to a cluster-like constellation of things which are held together in one point. In this lexically full meaning bunch can still be considered the head of the bi-nominal group, with the of-phrase functioning as a qualifier, spelling out what this bunch is actually composed of. Example (2) similarly refers to a literal pile of manure, highlighted by the premodifier foot-high; hence pile in (2) has to be attributed the same analysis as bunch in (1), viz. head status.

Examples (1) and (2) might not raise particular difficulties in interpreting the structural status of the $\mathrm{MN}$, but the problematic nature of the MNconstruction does come to the fore in an example like (3). Should we paraphrase it like (1) and (2), i.e. do the furniture and stuff constitute actual loads? Or, does the sentence simply mean 'a large quantity of furniture and stuff' without it necessarily being arranged in literal loads? In other words, does loads realize the function of quantifier or head? I will suggest that this question which has been treated rather vaguely and statically in mainstream grammatical approaches is best looked at as a case of ongoing delexicalization and grammaticalization (Section 2.3), with the by now more or less full-blown quantifier lots of as their historical precursor.

Example (4) is again much more straightforward; the abstract noun fun cannot be shaped into actual heaps. The MN in this sentence can thus be considered to function as a straight quantifier. The lexical meaning of heaps, viz. a specific 'constellation' of stuff, has bleached into a more or less purely grammatical 'quantity' meaning. The ambivalent example (3), then, can be considered to lie more or less in between the original, still fully lexical, use of the MN (examples (1) and (2)) and a grammatical meaning of the MN, viz. quantification of the noun in the ensuing of -phrase (cf. (4)).

The following sections will first survey two relevant theoretical accounts of MN-constructions. Section 2.1. discusses Halliday's analysis of what he calls “'measure' nominals" (Halliday 1985:173) and Section 2.2. sums up some of Langacker's (1991) pertinent insights into MNs. Taken together, the approaches of Halliday and Langacker, which link up naturally with grammaticalization studies, provide a cognitive-functional frame for analysing $\mathrm{MN}$ constructions. The remaining sections, then, report on the most important findings of a corpus study of MNs which I carried out, viz. two case studies focussing on a bunch of/bunches of and pile(s) of versus heap(s) of respectively. Since The Bank of English is restricted to language material of the last decade 
or so, the analysed corpus data in fact constitute synchronic slices, in which the observed structural ambivalence is indicative of processes of delexicalization and grammaticalization.

\section{Theoretical-descriptive starting point}

\subsection{Halliday's account of Measure Noun constructions}

Halliday (1985:173) deals with MN-constructions in a section following his exposé in favour of a twofold analysis of the nominal group on the ideational level, i.e. the level of lexicogrammatical organization concerned with the representation of experience.

Within the ideational level Halliday distinguishes between two 'layers', i.e. one in terms of constituency and one in terms of dependency. The constituency layer offers an analysis of the nominal group as a multivariate structure, i.e. as constituting a constellation of distinct functional slots which in some way characterize the Thing of the nominal group, which itself designates a class of entities and establishes the semantic core of the nominal group.

The dependency layer, on the other hand, analyses the nominal group as a univariate structure, viz. in terms of the recursive head-modifier relationship displayed by the nominal group.

In the default case the Thing of the experiential layer and the logical Head coincide. However, there are a few types of nominal group where Head and Thing do not coincide and "those involving a measure of something (...) [i.e.] 'measure' nominals” (Halliday 1985 173) are an example of such a discrep-

Table 1. Experiential structure of the nominal group

\begin{tabular}{lllllll}
\hline Deictic & Numerative & Epithet $_{1}$ & Epithet $_{2}$ & Classifier $^{\text {Thing }}$ & Qualifier \\
\hline those & two & splendid & old & electric & trains & with pantographs \\
\hline
\end{tabular}

Table 2. Logical structure of the nominal group (head-modifier)

\begin{tabular}{lllll}
\hline \multicolumn{2}{l}{ Premodifier } & Head & Postmodifier \\
& $\beta$ & $\alpha$ & $\beta$ & $\gamma$ \\
\hline those & electric & trains & with pantographs \\
\hline
\end{tabular}


Table 3. Twofold analysis of the nominal group; discrepancy Head/Thing (Halliday 1985: 173)

\begin{tabular}{lllll} 
A & pack & of & cards & \\
\hline & Numerative & & Thing & Experiential structure \\
\hline Modifier & Head & Postmodifier & & Logical structure \\
\hline
\end{tabular}

ancy between Head and Thing. Halliday goes on to analyse so-called "'measure' expressions" (ibid.: 169) in the following way:

In the logical structure, the measure word (pack, slice, yard) is Head, with the of phrase as Postmodifier. The Thing, however, is not the measure word but the thing being measured: here cards, bread, cloth. The measure expression functions as a complex Numerative. (Halliday 1985: 173)

This 'dual' analysis can be visualised by the box diagram for a pack of cards (Table 3):

\section{Halliday comments further that}

[i]t is not that one [analysis] is right and the other wrong; but that in order to get an adequate account of the nominal group, (...) we need to interpret it from both these points of view at once. [Italics LB] (Halliday 1985: 172-173)

This comment seems to imply a certain flexibility in the interpretation of MNconstructions. However, because it does not allow head status to shift from the 'measure' noun to the noun designating the matter being measured, it is hard to see how diachronic variation in the status of the MN can be captured.

What is unhelpful about the proposed dual analysis is that Numerative and Head status of the MN are divided over two simultaneous levels of analysis, thus suggesting that in each use the $\mathrm{MN}$ is always both. Halliday's observations hence turn out to be of little help in trying to get a grip on the distinct structural statuses of MNs as exemplified in examples (1) to (6). Rather than offering clear and systematic indications as to when a $\mathrm{MN}$ can be said to function as the head of the enclosing nominal group and when it has non-head status, the dual account in fact merely shifts the problem by dividing it over the two proposed levels of analysis.

Against this, the description of the MN proposed in this article will involve two distinct analyses, with the second one being treated as a re-analysis of the first: 


\begin{tabular}{|c|c|c|c|c|}
\hline $\begin{array}{l}\text { Lot } \\
\text { A pile }\end{array}$ & $\begin{array}{l}\text { of land } \\
\text { of paper }\end{array}$ & & $\begin{array}{l}\text { Lots of } \\
\text { Heaps of }\end{array}$ & $\begin{array}{l}\text { paper } \\
\text { people }\end{array}$ \\
\hline Head & Postmodifier & $-------\rightarrow$ & Quantifier & Head \\
\hline
\end{tabular}

Langacker's discussion of MNs, reviewed in the following section, does bring in the diachronic perspective lacking in Halliday's analysis. Langacker's account is, moreover, compatible with the framework that I will adopt in the actual case studies, viz. the study of grammaticalization.

\subsection{Langacker: the diachronic angle}

Langacker (1991) turns to the issue of MNs in his general discussion of the function of quantification in the NP. What is particularly interesting about Langacker's observations is that they immediately address the question of MNs from a diachronic angle, i.e. MNs as an emergent means of quantification.

Langacker's observations pertain to bi-nominal MN-phrases such as $a$ bunch of carrots, a bucket of water and a lot of sharks. He observes that "the nouns which appear as heads constitute a diverse and open-ended class." [italics LB] (Langacker 1991:88). MNs are by default attributed head status. He continues by remarking that

[s]ome of these nouns still have an interpretation in which they designate a physical, spatially-continuous entity that either serves as a container for some portion of the mass (bucket, cup, barrel, crate, jar, tub, vat, keg, box) or else is constituted of some such portion (bunch, pile, heap, loaf, sprig, head, stack, flock, herd). [italics LB] (Langacker 1991:88)

In addition, most of these nouns have developed a more figurative sense. Such semantic extensions are possible because the above MNs all incorporate "a conception of their typical size, which is part of their encyclopedic characterization." In the extended senses the physical entity designated by the MNs has become secondary to the size specification provided by the noun: "For instance, a bathtub may contain a bucket of water without there being any bucket in it - it is only implied that the water would fill a bucket were it placed in one." (Langacker 1991:88).

Or in other words (Langacker 1991 88-89): “The notion of a discrete physical object has faded, leaving behind the conception of a schematically characterized mass (the mass that, in the original sense, either fills or constitutes the 
object)." When a noun is interpreted in this way, it can, according to Langacker, be regarded as a quantifier.

He thus notices a diachronic process of bleaching of lexical meaning in certain MNs which may eventually lead to a reassessment of the structural status of the MN, viz. from head to quantifier. As we will see in the following section, such observations can be easily rephrased by using grammaticalization terminology. Langacker then concludes his discussion of MNs by stating that

A further step in this evolutionary sequence would be for the second noun to be reanalyzed as the head, leaving the remainder as a complex quantifier: [ $a$ lot of $\left.]_{\mathrm{QNT}}[\text { sharks }]_{\mathrm{N}}\right]_{\mathrm{NML}}$. I leave open the question of whether this reanalysis has actually occurred. (Ibid.: 89)

The aim of the corpus study reported on in this article is to provide some answers to both proposed re-analyses, viz. has N1 shifted from head to quantifier and $\mathrm{N} 2$ from postmodifier to head?

In conclusion to Langacker's account, we can say that it is interesting that he notes a diachronic shift with regard to the structural status of MN from head to quantifier, instead of the mere synchronic ambivalence proposed in mainstream grammars or the simultaneous layers in Halliday's analysis. Langacker also suggests that this grammatical re-analysis is paralleled by metaphorization and desemanticization of the MN. He therefore does accommodate the dynamic aspect of $\mathrm{MN}$-constructions by working with two distinct diachronic stages in the structural development of MN-constructions.

\subsection{Grammaticalization: diachronic and synchronic}

The framework which seems most suitable for tackling the specific developments encountered in MN-constructions is that of 'grammaticalization' theory, which not only does justice to these developments but also explains them. The developments displayed by $\mathrm{MN}$-constructions can then be regarded as a process of grammaticalization, which is moreover semantically-driven.

'Grammaticalization' itself has been defined in several ways (e.g. Haspelmath 1989; Fischer 1999 and Bybee 2001), but its essence is captured by Lehmann's (1985) definition, which is appropriately general and consists of a number of interesting parameters. Lehmann also distinguishes between diachronic and synchronic grammaticalization, a distinction that will prove useful when I discuss my case studies. Lehmann defines both types of grammaticalization as follows: 
Under the diachronic aspect, grammaticalization is a process which turns lexemes into grammatical formatives and makes grammatical formatives still more grammatical (cf. Kurylowicz 1965:52). From a synchronic point of view, grammaticalization provides a principle according to which subcategories of a given grammatical category may be ordered.

(Lehmann 1985 303)

The diachronic interpretation of grammaticalization nicely captures the developments and fluctuation encountered in MN-expressions: synchronically they often appear to hover indecisively between the class of quantifiers and head nouns as a consequence of a gradual move from lexical head to quantifier.

The synchronic interpretation of grammaticalization, then, can account for the fact that not all MNs have come to function as a quantifier to the same extent, i.e. there are individual differences with respect to the degree of their respective grammaticalization. It also invites us to draw up a scale of grammaticalization along which the various MNs looked at are positioned.

Lehmann proposes six parameters which define grammaticalization: attrition, paradigmaticization, obligatorification, condensation, coalescence and fixation. The first three pertain to paradigmatic aspects, the last three to syntagmatic aspects of the grammaticalizing item or string of items. Of these parameters, at least two clearly apply to $\mathrm{MN}$-constructions, viz. coalescence and semantic attrition. It is these two I will focus on in this article.

Coalescence is a syntactic criterion and concerns an increase in bondedness or syntactic cohesion of the elements that are in the process of grammaticalizing, i.e. what were formerly individually autonomous signs become more dependent on each other to the extent that they are increasingly interpreted as together constituting one "chunk", which as a whole expresses a (grammatical) meaning (cf. Bybee 2001:27).

The other relevant parameter, semantic attrition, is often referred to as delexicalization ${ }^{4}$ or loss of lexical content, and is commonly mentioned in grammaticalization studies as a symptom of grammaticalization processes. However, as Kurtböke (2001) correctly pointed out, one should be careful not to use 'delexicalization' as a mere synonym for 'grammaticalization'.

Both concepts will be operationalized for the actual corpus research in the following way. 'Delexicalization' will be identified in terms of a gradual broadening of collocational scatter or a loosening of the collocational requirements of the $\mathrm{MN}$ via such semantico-pragmatic processes as metaphorization, metonymization, analogy, etc. 'Grammaticalization', on the other hand, will be restricted to the actual grammatical re-analysis of a $\mathrm{MN}$ as a quantifier. In this particular study, delexicalization processes typically precede the 
actual re-interpretation of the MN as a quantifier. Delexicalization semantically paves the way, so to speak, for the actual grammaticalization to take place (Kurtböke 2001). Hence, these grammaticalization processes can be said to be semantically-driven (cf. Traugott 1988). Nevertheless, both concepts tend to remain intertwined because, in many cases, lexical and grammatical status are equally difficult to tease apart.

\section{Two case studies of MN-expressions}

In order to investigate the research questions formulated in Section 2 in terms of empirical, quantifiable data, corpus data from The Bank of English (COBUILD) were extracted on three MNs, viz. heap(s), pile(s) and bunch(es). The plural and singular forms of the MN were analysed as separate expressions.

This section will be organized as follows. Section 3.1. surveys the corpus study of bunch of and bunches of, primarily to demonstrate the subtle interaction between lexical and grammatical properties of the MN. In other words, it illustrates the fact that the grammaticalization process is semantically-driven. Furthermore, bunch of displays an additional development of a qualitative use that is very interesting because it draws strongly on the lexical origins of the $\mathrm{MN}$, even though the use itself is grammaticalized.

In Section 3.2. heap(s) of and pile(s) of will be compared from the point of view of "synchronic grammaticalization" (cf. Lehmann 1985), i.e. in terms of the extent to which both MNs have already grammaticalized. Such comparative analysis confirms that there are individual differences in the quantificational potential of the MNs looked at. This calls for explanations as to why certain MNs are more susceptible to delexicalization and grammaticalization than others. In addition to dissimilarity between semantically related words like heap and pile, there also seems to be a difference in the quantificational potential of the singular and plural variants of the various MNs.

It should be noted that each individual case study reveals general properties of MNs as such, as well as phenomena specific to individual MNs. The research question overarching both case studies is to gain insight into and chart the structural ambivalence observed in $\mathrm{MN}$-constructions. On a descriptive level this mainly amounts to assigning the corpus data to the categories 'quantifier', 'head' or 'vague'. Such relative frequency counts will allow us to draw quantitative profiles of the MNs looked at in terms of marked versus unmarked use (cf. Halliday \& James 1993) and see to what extent quantifier uses are attested 
in actual corpus data as opposed to head uses of MNs. We will approach head versus quantifier use of the MNs in terms of Halliday's probabilistic grammar, which conceives grammar as systems of choice, in this case the choice between using MNs as head or quantifier. Halliday distinguishes between equi-probable and skewed systems (Halliday \& James 1993). In equi-probable systems both options are equally probable and neither choice is marked. Skewed systems, on the other hand, display a $90 \%$ versus $10 \%$ proportion between options of which one is unmarked. Statistical markedness is hence taken to reflect functional markedness.

In assessing the structural status of the MNs two main types of tests were used, viz. semantic and syntactic ones. The semantic criteria pertain to the degree of lexicality of the MN and its collocational range. The main guideline here was that the more literal and lexically specific in meaning the $\mathrm{MN}$ is, the more likely it will constitute the head of the enclosing NP. This of course interlocks with the type of noun featured in the of-phrase. Literal and fully lexical uses generally predict a restricted set of collocates in the of-phrase. Hence, as the collocational range of the $\mathrm{MN}$ increases, the probability of quantifier status of the MN likewise increases.

Syntactic criteria pertain to number concord with finite verbs and anaphoric pronouns, in the sense that the element in the bi-nominal MN-phrase determining the number of the verb or pronoun is generally taken to be the head of the phrase. However, syntactic criteria such as subject-verb agreement have only limited applicability, since the latter only applies when the bi-nominal MN-phrase appears in subject position. Furthermore, for this criterion to be truly verifiable, the $\mathrm{MN}$ and N2 have to differ in number. Such restrictions very often prevent a systematic syntactic corraboration of the status of the MN. Moreover, in transitional cases fluctuating verb agreement may be indicative of vacillating grammatical behaviour as such. Nevertheless, if syntactic criteria converge with semantic indications of head status, they can be taken into account, as in the following examples:

(i) The fox, unable to reach a bunch of grapes that hangs too high, decides that they were sour anyway.

(ii) Six plane loads of food are also being flown today to the city of Mogadishu.

(iii) There's now a whole bunch of studies from different cities that show the same thing. 
The assessment criteria yield two obvious categories, viz. Head versus Quantifier. Yet, a considerable amount of corpus data resisted conclusive categorisation as either head or quantifier, because the MNs proved to be inherently vague between both. The vague category hence subsumes those corpus examples that do not allow and in fact do not need disambiguation of two separate readings (see Geeraerts 1993 on lexical vagueness). Grammaticalization studies mostly discuss 'vagueness' in terms of phases of transition from an older meaning to a new one within the larger development, yet rarely as an end stage, whereas the grammaticalization processes of the MNs looked at seem to suggest precisely that. Even if the various MNs grammaticalize further, some uses will most probably retain some inherent vagueness.

\subsection{Bunch(es) of: the MN-continuum}

\subsubsection{Semantically - driven grammaticalization}

Bunch is particularly interesting because it gives an indication of the diversity in $\mathrm{MN}$ - uses that can be found along the path of increasing delexicalization and grammaticalization. This is mainly due to the fact that with regard to these processes bunch, as opposed to heap and pile, has a particularly clear initial stage, as well as a readily identifiable end stage. As such, the bunch corpus displayed $\mathrm{MN}$-uses spanning the entire MN-continuum and in particular uses occupying the two extremes of the scale, viz. a fully lexical head noun use as well as numerous instances of fully grammaticalized quantifier uses.

At the first stage in the entire development, bunch has a readily identifiable head noun use, which is still fully lexical and literal in meaning. It is collocationally restricted to a rather limited set of postmodifying nouns, viz. flowers (and hyponyms), grapes, bananas, carrots and other nouns such as herbs and similar (co-)hyponyms.

In this pre-delexicalization and pre-grammaticalization stage bunch attributes a specific arrangement to the things designated in the of -phrase or it designates the typical constellatory appearance of the latter. More specifically, bunch refers to a somewhat unruly cluster of things fastened at one point, holding the component parts together. "Prototypical examples of bunches are grapes, bananas, or other pluralities of individuals which are tightly tied together, such as carrots, parsley, radishes, or cut flowers. (...) 'A bunch is more untidy and less focussed than a cluster.' (Lehrer 1986:118 and K. Allan pc, cited in Lehrer 1986). Its quantificational import is hence restricted to that of 
a $\mathrm{MN}$ in the narrow sense: it specifies the standard portion or prototypical constellatory appearance of the things designated in the of -phrase.

Corpus attestation of this original head use is very small for singular bunch, whereas it is the predominant or even near-exclusive use of plural bunches. The percentages of Head and Quantifier use of bunch(es) of are represented in Table 4 below: $3 \%$ head status versus $97 \%$ quantifier status for bunch, while bunches appears as head in $98 \%$ of the cases with only $2 \%$ having quantifier/vague status.

Sentences one to three are clear illustrations of the collocationally restricted literal use of bunch and bunches.

(1) The fox, unable to reach a bunch of grapes that hangs too high, decides that they were sour anyway.

(2) The greens all looked particularly fresh and succulent: furled, pale green Chinese leaves, deeper green, spoon-shaped bok choi, floppy bunches of Chinese water spinach and the elegantly fluted leaves of Chinese kale.

(3) They walked to a reserved table in the basement, where Jimmy had put a huge bunch of white roses. ${ }^{5}$

In examples (1) to (3) bunch or bunches unmistakably constitute the head. Even though the MN-expressions do not always occur as subjects, the singular verb in (1) for instance strongly suggests that it is the MN that controls verb agreement and not plural grapes. There are also several semantic indications for attributing head status to bunch(es) in the above examples: the lexical semantics of bunch(es) strongly invoke the notion of a specific constellation, which imposes rather strict collocational requirements on the noun in the following of phrase. The individual modification of both nouns (i.e. MN and N2) in these examples also stresses the independence of the MN. This again is in keeping

Table 4. Percentages and figures for the bunch of and bunches of corpora

\begin{tabular}{|c|c|c|c|c|c|c|c|}
\hline \multirow{4}{*}{ Bunch of } & \multicolumn{2}{|c|}{ Head } & \multicolumn{2}{|c|}{ Quantifier } & \multirow{4}{*}{$\begin{array}{l}\text { Plural countable } \\
\text { uncountable } \\
\text { human/animate }\end{array}$} & \multirow{4}{*}{$\begin{array}{l}15 \% \\
15 \% \\
70 \%\end{array}$} & \multirow{4}{*}{$\begin{array}{l}44 \\
43 \\
204\end{array}$} \\
\hline & $3 \%$ & 9 & $97 \%$ & 291 & & & \\
\hline & & & & & & & \\
\hline & & & & & & & \\
\hline & \multicolumn{2}{|c|}{ Head } & \multicolumn{2}{|c|}{ Vague } & & & \\
\hline Bunches of & $98 \%$ & 49 & $2 \%$ & 1 & & & \\
\hline
\end{tabular}


with Lehmann's parameters, which all boil down to a decrease in autonomy of the grammaticalizing sign (cf. Section 2.3).

In subsequent stages the constellatory meaning expressed by 'bunch' increasingly bleaches, which opens up collocational possibilities with regard to the type of noun that can appear in the N2 slot. Whereas at stage $1 \mathrm{~N} 2$ had to designate a physical or tangible object, and moreover a collocationally restricted subset of these, such as flowers, fruit, etc., we gradually move to a stage where abstract nouns are allowed to feature in the of -phrase as well.

Parallel to the further delexicalization of $a$ bunch of, the expression will be increasingly interpreted as constituting one indivisible chunk which as a whole expresses its quantifying function; or in other words "autosemantic signs become synsemantic signs" (cf. "coalescence" in Lehmann 1985 308, and Bybee 2001:27).

It is interesting to note here that bunches has not reached the end stage of delexicalization and grammaticalization yet, which was already clear from the percentages cited earlier. However, the corpus did include a few examples in which bunches is to some extent intermediate or vague between true head status and full-blown quantifier status (even though these instances still seem to gravitate more towards head status). Vague cases were not attested for singular bunch of, the data of which clearly presented the two extremes of MN-uses, viz. head versus quantifier. In this respect bunch of differs from heap(s) of and pile(s) of, the corpus data of which did include a considerable amount of vague instances (see Section 3.2).

The 'vague' category hence is restricted to about two sentences with bunches. Both can be said to have delexicalized to some extent, since the MNexpression typically teams up with animate nouns, on the basis of a metaphorical extension. Sentence (4) is in fact the one most truly vague between head and quantifier status:

(4) They had bunches of erm they had bunches of skinheads standing around on the stage going "Sod off".

In (4) the skinheads might be forming actual human clusters, but the sentence might just as well simply mean 'a lot of skinheads', in which case bunches would be a quantifier. Still, the 'vague' category is very small for bunches. In those cases a lot of potential lexical meaning is associated with the quantifier use.

For a bunch of, however, systematic delexicalization and grammaticalization has taken place to the extent that no truly vague cases were attested. Collocational requirements imposed by the $\mathrm{MN}$ are increasingly loosened, enabling 
Table 5. Grammaticalized quantifier use of a bunch of

\begin{tabular}{ll}
\hline Inanimate plural & (5) There's now a whole bunch of studies from different cities that \\
countable noun & (6) Traditional advertising pictures are a bunch of lies. \\
(7) Ned wanted to give me a bunch of suits.
\end{tabular}

+Uncountable noun (8) Trouble was, the funds were able to neatly hide all but the most conspicuous of their charges in a bunch of legalese.

(9) We started in May and did a bunch of practising.

(10) I spent a bunch of time, when I was visiting the county, talking to his neighbours.

+Human/animate

(11) Who said Americans were a jingoistic bunch of rednecks who plural countable know or care nothing about what happens beyond their shores? noun

(12) Deng was pictured taking a dip with a bunch of his beaming buddies at a summer resort in the north of the country.

(13) Russia and America were just a bunch of enthusiastic and very fit guys who ran around for 80 minutes without much method.

(14) We guarantee the noble young lord will complain about having to spend time with such a boring bunch of geriatrics.

bunch to be used with plural count nouns irrespective of their semantics. Furthermore, as mentioned earlier, a bunch of is also extended to abstract uncount nouns that surely cannot occur in literal 'bunches' at all, which testifies to the fact that the quantifying function of the MN has become prevalent and possibly exclusive in such instances. The lexical 'arrangement' meaning of bunch has thus faded into a purely quantifying meaning by means of the typical 'size implications' of the MN, a developmental path which was pointed out by Langacker (1991:88), see Section 2.2.

Consider the examples of a grammaticalized quantifier use of $a$ bunch of combined with plural count nouns (animate and inanimate) as well as uncount nouns in Table 5 .

Examples (5) to (7) show that we have clearly moved away from the restricted set of collocates found at stage 1, to the extent that the $\mathrm{N} 2$ slot is open to diverse types of plural count nouns, abstract (cf. 6) as well as concrete (cf. 7) ${ }^{6}$ Examples (8) to (10) illustrate yet a further delexicalized use of bunch that can be found with abstract uncount nouns. In examples like (5) and (8), e.g. What a bunch of gobbledygook! the quantifier use can be explained by a metonymic shift. On the level of representational semantics, the extension to a noun designating linguistic entities, such as gobbledygook can be explained as 
a metonymic shift from (stackable) legal files and reports and studies on paper to plain intangible 'legalese' construed as an abstract mass. Another important motivation for turning certain MNs into means of quantification is of an interpersonal nature, viz. the need for (hyperbolic) expressiveness. This is even more important in the grammaticalization process of heaps (see Section 3.2).

The important thing, however, is that bunch can be systematically used as a quantifier with abstract uncount nouns without many restrictions as to the specific semantics of those nouns and without leading to marked or quirky sentences.

Besides numerous appearances with plural count nouns and abstract uncount nouns, corpus analysis reveals that in its grammaticalized quantifier use bunch of is predominantlty used to quantify a number of people. Approximately $70 \%$ of the true quantifier attestations pertain to human (and animate) plural count nouns. The remaining $30 \%$ is, by and by, evenly spread over the plural count nouns and the uncount nouns. Bearing in mind that the original literal use of bunch is limited to approximately three percent of the entire corpus, we can safely conclude that bunch of has grammaticalized very significantly already and has in fact become the unmarked use of this MN. Moreover, this quantifier use is very much oblivious to the original lexical semantics of bunch.

The latter statement might need to be nuanced to some extent in the light of the development of a further, qualitative use specific to bunch of, which is particularly observable with regard to human plural count nouns. This secondary qualitative use in fact does draw on the original lexical meaning of 'bunch', even though it is a grammaticalized use.

At stake is the feature of 'unruliness' (cf. Allan 1977), which was already present in the original lexical semantics of 'bunch' (see e.g. example (13) above). Whereas at stage 1 this feature pertained to the particular manner of arrangement, it now comes to apply metaphorically to the morality, in a broad sense, of the people being quantified. By using a bunch of to quantify 'human' nouns, the latter are also, and mostly negatively, qualified. We can speak here of a 'semantic prosody' as defined by Sinclair (1992) and Bublitz (1996): a negative, or occasionally positive, semantic aura spreading from node to collocate. The negativity is not connotated by bunch as such, but is prosodic in nature, viz. bunch radiates "a specific halo", "[i]t prospects ahead and 'sets the scene' (Sinclair 1992:8) for a particular type of subsequent item”. It thereby creates a strong expectation with regard to the polarity of N2, "based on a semantically consistent set of collocates." (Bublitz 1996: 11). 
Collocates typical of this semantic prosody are inherently negative human nouns such as rednecks, no-hopers, bastards, do-nothings, etc. Very often bunch itself is premodified by similarly negative evaluative adjectives, such as jingoistic and boring in (11) and (14) (see Section 3.1.2). It is only with regard to young people, students, kids and the like that bunch of can be used less negatively. In such cases the 'unruly' aspect can be considered to be charming or justified as a sign of youthful vivaciousness for instance. In expressions such as a bunch of guys/lads/etc. there is the additional suggestion of bondedness, of a close-knit group of amicable people. This can be seen as a metaphorical revival of the original 'cluster' semantics.

Similar semantic prosody effects arise when a bunch of is combined with inanimate plural count nouns, e.g. (6), or uncount nouns, e.g. (8); in those cases too N2 itself mostly carries a negative feature. However, even without such explicit or inherent negativity markers, grammaticalized a bunch of tends to trigger off negative polarity. It is not always clear whether such additional semantic features or inferential extras as 'behavioural unruliness' (or sometimes 'youthful exuberance'), 'condescension' and 'minimization'/'slighting'7 are 'connotations' or whether the concept of 'semantic prosody' as defined earlier is descriptively most accurate. The corpus analysis seems to suggest that grammaticalized bunch of does very much predict negative collocates. Hence the way in which bunch "rubbs off" its negativity suggests that semantic prosody is at stake.

This is further corroborated by examples like (6), (8) and (11), which display a very productive quantifier use of bunch, giving rise to almost idiomatic chunks. ${ }^{8}$

\subsubsection{Premodification patterns}

Another important issue is the potential premodification patterns of both bunch and N2, especially with regard to Lehmann's parameter of the increase in bondedness in grammaticalizing constructions (see Section 1.3). There are some interesting shifts in the premodifying potential of both nouns concomitant with the increase in grammaticalization.

The premodifiers found with bunch can be subdivided into two types parallel with the two grammaticalized uses of bunch of discussed earlier. Firstly, in its grammaticalized quantifier function bunch can be submodified by adjectives expressing quantity, which further foreground that quantifying function. Examples are (5) There's now a whole bunch of studies from different cities that show the same thing and (15) Place a good bunch of calf tail into your stacker. In exam- 
ples like these, whole and good reinforce the quantifier meaning of bunch. The actual quantity expressed by bunch varies, but seems to be considerably large, although less than heaps or piles. Bunch seems to suggest 'somewhat more than could be reasonably expected' and 'no lack of'. A good/whole bunch hence goes somewhat beyond such 'large but within bounds' meaning.

Secondly, we have seen that bunch of also incorporates a qualitative meaning, which can likewise be highlighted by means of evaluative adjectives submodifying bunch, as in (11) Who said Americans were a jingoistic bunch of rednecks who know or care nothing about what happens beyond their shores?; (14) We guarantee the noble young lord will complain about having to spend time with such a boring bunch of geriatrics and (16) The whole team had begun snapping at each other like a squabbling bunch of stray dogs.

Qualitative modification of bunch of seems to involve a transfer of the qualitative modifiers of N2 to N1 (Halliday 1985:174) as in examples (11), (14) and (16). However, qualitative adjectives ascribed to N2 do not necessarily have to move to the pre-MN modifier slot, as shown by (13) Russia and America were just a bunch of enthusaistic and very fit guys who ran around for 80 minutes without much method. Interesting in this respect are the following two corpus examples which both feature the qualitative adjective great, alternatively in pre-N2 position and in pre-bunch position:

(17) Aren't we a bunch of great guys?

(18) I'm racing with a great bunch of guys and it makes racing fun again.

The relocation of the qualitative adjective does bring about some differences in meaning. In (17) great applies as a qualitative adjective to guys. In (18) on the other hand, the unity or group aspect of the guys is highlighted and further qualified as something great.

Overall an actual 'shift' of qualitative adjectives from N2 to pre-MN position does not seem to be systematically predictable, but is rather ad hoc and pragmatically motivated. All we can say is that, firstly, only qualitative adjectives come in for positional transfer, as exemplified by the ungrammaticality of (19a) versus (19), both with classifying UEFA:

(19) Andy Roxburgh bumped into a bunch of UEFA officials (19a)*Andy Roxburgh bumped into a UEFA bunch of officials. 
Classifying adjectives and nouns indicate a subclass of the type expressed by the head noun and hence are typically non-gradable, as opposed to qualitative adjectives (Halliday 1994).

Secondly, it should be noted that whereas qualitative modification of the $\mathrm{MN}$ is the result of the qualitative adjective being relocated, quantitative modification is not. Instead it is the result of adding an extra piece of quantitative information directly to the quantifier bunch.

In conclusion to this section we can say that singular bunch has grammaticalized to a much greater extent than its plural counterpart, the corpus data of which displayed a near-exclusive head use.

Overlaying the grammaticalized quantifying function of bunch in some cases is a qualitative use motivated by the metaphorization of the 'unruly' feature. For the two main grammaticalized uses, distinct modification patterns can be distinguished.

3.2 Heap(s) of and pile(s) of: a comparative study of degree of grammaticalization

\subsubsection{Research question: "synchronic grammaticalization"}

In this section the MNs heap and pile are compared in terms of their respective degree of grammaticalization. From the vantage point of grammaticalization studies, this research question is captured by Lehmann's concept of "synchronic grammaticalization" (Lehmann 1985 303, 305).

"From the synchronic point of view, grammaticalization provides a principle according to which subcategories of a given grammatical category may be ordered." (ibid.: 303). In this way, synchronically co-existing "structural devices" for expressing a given grammatical function can be ordered by setting them out on a cline reflecting their respective degree of grammaticalization (ibid.: 303, 305). This section will thus compare the proportion of quantifier uses found with pile(s) of and heap(s) of, but later on a more complete scale will be drawn, partly based on corpus analyses that will not be described in detail (i.e. for load(s) of). Naturally this also raises the question why certain MNs might be more susceptible to delexicalization and grammaticalization than others.

\subsubsection{Case study: heap(s) of versus pile(s) of}

The MNs pile(s) of and heap(s) of differ from bunch of, in that they do not have the clear point of departure in their delexicalization and grammaticaliza- 
tion process that bunch of had. Nor do the data for heap(s) and pile(s) clearly dichotomize into head or quantifier without vague cases.

Their delexicalization processes in particular lack a clear first stage, because pile(s) of and heap(s) of do not have a literal meaning tied to a very restricted set of collocates, which bunch did have (e.g. a bunch of flowers/carrots/bananas). In fact, in the first literal stage the only restriction on N2 is for its referent to be able to be made into a pile/heap. However, this still leaves considerable room for variation, since virtually everything can be stacked, both animate and inanimate concrete 'things'. One cannot, at first sight, indicate clear differences in collocational patterns between both nouns.

However, analysis of pile/piles and heap/heaps in corpora reveals significant dissimilarities in terms of head-quantifier proportions for the two MNs, manifested most strongly for their plural forms. The following table sums up the quantifier versus head percentages for heap of, heaps of, pile of and piles of with examples illustrating the various categories.

'HEAPS OF'

\begin{tabular}{|c|c|c|c|c|}
\hline \multirow[b]{2}{*}{ Head } & \multirow{2}{*}{$\begin{array}{l}\text { Tokens } \\
29\end{array}$} & \multirow{2}{*}{$\begin{array}{l}\text { Percentages } \\
32.22 \%\end{array}$} & \multicolumn{2}{|c|}{ Examples } \\
\hline & & & (20) & $\begin{array}{l}\text { Pulham, scion of the Portland cement family, experimented and per- } \\
\text { fected in the } 1840 \text { s the art of using liquid cement poured over heaps of } \\
\text { clinker to make rock formations. }\end{array}$ \\
\hline \multirow[t]{2}{*}{ Quantifier } & 59 & $\underline{65.56 \%}$ & (21) & $\begin{array}{l}\text { What's interesting is how many sexual researchers and observers were } \\
\text { driven by self-interest? Heaps of them at least. }\end{array}$ \\
\hline & & & (22) & $\begin{array}{l}\text { The graphics are very polished, with pitch detail, markings and the like } \\
\text { to add heaps of atmosphere. }\end{array}$ \\
\hline \multirow[t]{2}{*}{$\begin{array}{l}\text { Transition/ } \\
\text { 'Vague' }\end{array}$} & 2 & $2.22 \%$ & (23) & $\begin{array}{l}\text { I cook it the way they do in Badajoz, with heaps of garlic and a touch of } \\
\text { spice. (biased to the 'quantifer' category) }\end{array}$ \\
\hline & 90 & $100 \%$ & & \\
\hline
\end{tabular}

'PILES OF'

\begin{tabular}{|c|c|c|c|c|}
\hline \multirow[b]{2}{*}{ Head } & \multirow{2}{*}{$\begin{array}{l}\text { Tokens } \\
159\end{array}$} & \multirow{2}{*}{$\begin{array}{l}\text { Percentages } \\
92.98 \%\end{array}$} & \multicolumn{2}{|c|}{ Examples } \\
\hline & & & (24) & $\begin{array}{l}\text { There was no memory of summer but the little sad piles of hay that } \\
\text { rotted in the fields. }\end{array}$ \\
\hline $\begin{array}{l}\text { Non- } \\
\text { Head/Q }\end{array}$ & 8 & $4.68 \%$ & (25) & $\begin{array}{l}\text { Mike Atherton has been warned he must score piles of runs for Lan- } \\
\text { cashire to keep his England test place. }\end{array}$ \\
\hline $\begin{array}{l}\text { Transition/ } \\
\text { 'vague' }\end{array}$ & 4 & $2.34 \%$ & (27) & $\begin{array}{l}\text { Leshan emphasizes a remark by G. B. Shaw that Lourdes is the most } \\
\text { blasphemous place on the face of earth: mountains of wheelchairs and } \\
\text { piles of crutches exist, "but not a single wooden leg, glass eye, toupe[e]!". } \\
\text { The real fun begins when you start receiving piles of property details. } \\
\text { ('paper' metonymy) }\end{array}$ \\
\hline & 171 & $100 \%$ & & \\
\hline
\end{tabular}




\begin{tabular}{|c|c|c|c|c|}
\hline \multirow[b]{2}{*}{ Head } & \multirow{2}{*}{$\begin{array}{l}\text { Tokens } \\
58\end{array}$} & \multirow{2}{*}{$\begin{array}{l}\text { Percentages } \\
55.24 \%\end{array}$} & \multicolumn{2}{|c|}{ Examples } \\
\hline & & & $(28)$ & $\begin{array}{l}\text { "My first impression was not that it was an earthquake," said Heinz Her- } \\
\text { manns, standing by a heap of bricks that had fallen from his } 100 \text {-year-old } \\
\text { house. }\end{array}$ \\
\hline $\begin{array}{l}\text { Non- } \\
\text { Head/Q }\end{array}$ & 41 & $39.05 \%$ & $(29)$ & $\begin{array}{l}\text { They went through my bags, searched me and asked me a heap of ques- } \\
\text { tions. }\end{array}$ \\
\hline \multirow[t]{4}{*}{$\begin{array}{l}\text { Transition/ } \\
\text { 'vague' }\end{array}$} & 6 & $5.71 \%$ & $(30)$ & $\begin{array}{l}\text { That deadly, winking snuggling } \frac{\text { chromium-plated, }}{\text { scent-impregnated, }} \\
\text { luminous, } \frac{\text { quivering, }}{\text { giggling, }} \text { fruit-flavoured, mincing, ice-covered } \\
\text { heap of motherlove [said about Liberace] }\end{array}$ \\
\hline & & & (31) & $\begin{array}{l}\text { The British have forged a fine tradition of gardening and cannot afford } \\
\text { to sit on their well-clipped laurels. Striding past the compost heap of } \\
\text { nostalgia, comes Christopher Lloyd. }\end{array}$ \\
\hline & & & $(32)$ & $\begin{array}{l}\text { He test-fired a dozen of Hellfire missiles at a fleet of old Saudi school } \\
\text { buses, reducing the vehicles to a heap of springs and blackened chassis. }\end{array}$ \\
\hline & 105 & $100 \%$ & & \\
\hline \multicolumn{5}{|l|}{ 'PILE OF' } \\
\hline & Tokens & Percentages & \multicolumn{2}{|c|}{ Examples } \\
\hline Head & 176 & $88.44 \%$ & (33) & $\begin{array}{l}\text { A jilted girlfriend got revenge on the boyfriend who dumped her by } \\
\text { dumping a foot-high pile of manure in his bed. }\end{array}$ \\
\hline \multirow[t]{2}{*}{$\begin{array}{l}\text { Non- } \\
\text { Head/Q }\end{array}$} & 6 & $3.02 \%$ & $(34)$ & $\begin{array}{l}\text { I can just see a whole pile of the boys walking out after the final and } \\
\text { saying bye bye. }\end{array}$ \\
\hline & & & $(35)$ & It [i.e. a performance] was the biggest pile of want ever. \\
\hline \multirow[t]{3}{*}{$\begin{array}{l}\text { Transition/ } \\
\text { 'vague' }\end{array}$} & 17 & $8.54 \%$ & $(36)$ & $\begin{array}{l}6 \text { CAMMY MURRAY: Recovered well after a nervous start and put in a } \\
\text { pile of strong defensive work. ('(paper)work'-metonymy; here more or } \\
\text { less 'Quantifier')) }\end{array}$ \\
\hline & & & $(37)$ & $\begin{array}{l}\text { If you go and have a look next door there's a great pile of work that builds } \\
\text { up. ('paperwork' metonymy; leans more towards the 'Head' category } \\
\text { here) }\end{array}$ \\
\hline & 199 & $100 \%$ & & \\
\hline
\end{tabular}

\section{Summary:}

\begin{tabular}{llll}
\hline & HEAD & QUANTIFIER & TRANSITION \\
\hline 'HEAPS OF' & $32.22 \%$ & $\underline{65.56 \%}$ & $2.22 \%$ \\
'HEAP OF' & $\underline{55.24 \%}$ & $39.05 \%$ & $5.71 \%$ \\
'PILES OF' & $\underline{92.98 \%}$ & $4.68 \%$ & $2.34 \%$ \\
'PILE OF' & $\underline{88.44 \%}$ & $3.02 \%$ & $8.54 \%$ \\
\hline
\end{tabular}

Table 6. Figures for heap(s) of and pile(s) of 
The 'vague' or 'transition' category again subsumes corpus attestations that are vague between a head and a quantifier reading, in the sense that both interpretations come about in a more or less similarly natural way. The category often includes metaphorical or otherwise highly expressive stretches of discourse, which precisely exploit the categorial ambivalence of MNs by appealing to their original lexical meaning as well as the (grammatical) quantifier status.

From the percentages we can conclude that heap has an overall lead over pile in the grammaticalization process. Singular heap of still tends towards an equi-probable system, with $39.05 \%$ of the data being quantifier and $55.24 \%$ head; in this case head and quantifier use of heap of are almost equally probable (Halliday \& James 1993: see Section 2).

For the plural, however, there is a more pronounced skew towards the quantifier use, which amounts to $65.56 \%$. Both pile of and piles of clearly skew in the other direction with a predominant head use: $88.44 \%$ for pile of and 92.98\% for piles of. Skew systems, rather than presenting options as equally probable, present one option as considerably more frequent and unmarked than another option.

The reason for the differing degree to which pile and heap have grammaticalized, in my opinion, has to be sought in differences in the delexicalization process. There seems to be a fundamental difference in the delexicalization potential of both MNs, in its turn dependent on certain lexico-semantic properties inherent in the respective concepts of 'pile' and 'heap'. Compare the following constructed MN-nominals, which alternatively have heaps of and piles of followed by the same nouns; the collocational restrictions on the quantificational use of piles of are immediately obvious.

(38) piles of stones/paper/people

(39) heaps of stones/paper/people

In (38) piles is analysed as the head noun, irrespective of N2, whereas in (39) a pure quantifier reading of heaps of is just as natural as a literal one with regard to stones and paper, even though their referents are prototypically stackable. Moreover, the quantifier reading is even the unmarked reading when heaps of is combined with the animate noun people. Piles of people, on the other hand, sounds strange as a quantifier reading.

As suggested earlier, the difference in extent of grammaticalization can be explained by differences in the delexicalization potential inherent in the respective concepts of 'pile' and 'heap'. (38) for example shows that 'Pile' calls up 
a vertical dimension and the idea of being intentionally constructed. According to The Concise Oxford Dictionary a pile is "a heap of things laid or gathered upon one another."(italics LB), incorporating the notion of construction by some agent. A 'heap', on the other hand, is defined as constituting merely "[a] collection of things lying haphazardly one on another." (italics LB), which lacks the idea of constructional solidity. ${ }^{9}$ The concept of 'heap' is hence in itself already semantically more vague and internally more chaotic than that designated by 'pile', which very much aids further delexicalization and subsequent grammaticalization (compare Bybee 2001 9). 'Heap' profiles the idea of an undifferentiated mass, from which it is easier to detach a mere 'quantity' meaning than is the case with 'pile'. Hence, the quantifier uses of pile of attested in the corpus data do not represent systematically productive uses.

The corpus study also made clear that pile's inherent conceptual resistance to semantic generalization is matched by a rather restricted collocational extension. When functioning as head, pile of exclusively combines with concrete nouns, which are furthermore restricted to the prototypically stackable kind, such as rubble, papers, letters, bricks, etc. Pile hence does not have much collocational stretch to start with.

In the few instances in which it can be considered to function predominantly as a quantifier the nouns in the of -phrase are mostly uncountable and abstract, which seems to suggest an increase in delexicalization. However, such an extension is restricted to a specific set of abstract nouns denoting a negative concept, usually a lack of quality. It is also the most productive quantifier use of pile. Examples (40) to (42) illustrate this use. ${ }^{10}$

(40) It [i.e. an album] is the biggest pile of pretentious tosh I've ever heard this year.

(41) It [i.e. a performance] was the biggest pile of want ever.

(42) Give four students three million quid and I bet they'd come up with something ten times better than this pile of arty old toot.

Of course this means that a certain amount of collocational loosening has taken place, since in its literal use pile of could only combine with concrete nouns, either countable or uncountable, but always referring to physical objects and tosh, want and toot are clearly abstract nouns. Still, I do not think examples (40) to (42) indicate a systematic loosening of collocational requirements as such. One way of explaining the combinatory extension to these particular abstract nouns is to consider them as metaphorical translations of the literal rubbish 
etc. pile(s) of so often appears with when functioning as head. Pile of combines only once with a concrete plural noun, which was moreover animate:

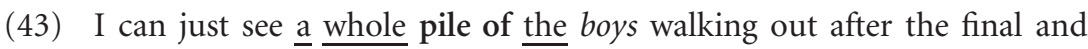
saying bye bye.

However, the choice of pile of as a quantifier has an oddity about it which heaps of + animate noun does not have. At this point in time pile of is still a very marked means of quantification and is restricted to very specific contexts or otherwise used with an expressive purpose in mind.

In addition to the quantifier use in examples (40) to (42), examples (44) to (47) illustrate another use of pile(s) that might become systematically productive on the basis of a rather straightforward metonymy:

(44) If you go and have a look next door there's a great pile of work that builds up because they haven't got anybody to get it back into the system.

(45) He put in a pile of strong defensive work.

(46) The real fun starts when you start receiving piles of property details.

(47) This silly hospital story has piles of jokes in it.

It was mentioned earlier that one of the main lexical fields that pile of draws its collocates from has to do with paper and the like. Via metonymy a pile of work can shift in meaning from designating an amount of (paper)work which literally takes the shape of a pile (as in (44)) to simply denoting an amount of work, no longer presenting itself as a pile. In (46) and (45) we have arrived at the latter stage, with (45) even pertaining to an effort in sports activities.

Other corpus examples with work still seem to be in pre-metonymization stages, while others are at least vague between a literal and a quantifier reading of pile of. It mostly comes down to contextual clues in order to decide whether the pile is literal or not. For instance, builds up in (44) enhances a literal reading of pile by stressing that it is an actual object that occupies a certain amount of space and has a specific vertical build-up. (46) and (47) can likewise be traced to the paper(work)-metonymy. In (46) there is a shift from quantifying papers with property details on them to quantifying the property details as such. A similar metonymic shift can be observed in (47).

In sum, it seems that all nouns referring to some act of verbalization, either written or spoken, are open to this kind of metonymy and, when systematically exploited, this process may lead to a more productive quantifier use of pile(s) of. The lexical field of fruit and vegetables poses similar possibilities. Money is 
also a transitional area, which can perhaps also be subsumed under the 'paper' category, since the corpus examples always referred to banknotes.

Besides lexicogrammatical motives such as metaphorization (40-42) and metonymization (44-47), there is also a pragmatic motivation for the quantifier use of pile, viz. the need for hyperbolic expressiveness. Frequent use of quantifier expressions decreases their intensifying potential, hyperboles become conventionalised and this creates a need for new ones. In providing such a hyperbolic means of quantification, pile is analogous to load in a load of bullshit, etc.

Grammaticalization theory refers to all this as an instance of renewal, i.e. "the process whereby existing meanings may take on new forms" (Hopper \& Traugott 1993:121). Informal intensifying expressions in particular are noted to be susceptible to renewal; during different periods different expressions are fashionable. For instance, at some point everything seemed to come in bags: bags of fun, etc. (Halliday, personal communication). Renewed forms themselves may become subject to grammaticalization in their turn in what is essentially a cyclical process of renewal and routinization (Hopper \& Traugott 1993: 123).

Summing up our observations of pile of, we can conclude that it has a smaller proportion of quantifier uses than heap(s) of and bunch of, which can be explained by the inherent denotative meaning of the former, which prevents it from sufficiently loosening its collocational requirements. In addition, there is the interpersonal factor of renewal or 'conventions' of the period to keep in mind. Despite the current resistance of pile(s) of to systematic quantifier use, we can predict certain developments that might bring about such a productive quantifier use in the future. Metonymies such as the (paper)work one may lead to a loosening of collocational requirements and loss of literal semantic features, which proved essential in the grammaticalization processes of heap (s) of and bunch of. Interpersonal analogies, such as with a load of, for the intensifying and negative meanings of pile(s), should not be underestimated either.

In contrast to pile, heap has developed a productive quantifier use. This was explained earlier in terms of an observed difference in the delexicalization potential of heap and pile. The persistence of constructional verticality in the concept of pile at this point in time turned out to be a blocking factor in the preliminary delexicalization process. Heap, on the other hand, has horizontal potential because of the 'disorderliness' and lack of intentional construction typically associated with it, which are moreover conducive to further collocational loosening and ensuing grammaticalization. This is confirmed by the 
considerable amount of variety in the types of nouns that can combine with heap(s) of when used as a quantifier, whereas pile continues to impose rather strict collocational requirements.

When functioning as head, heaps of has the same set of collocates as pile(s) of, viz. concrete nouns of the stackable kind, which can be either countable or uncountable. However, pile(s) of mostly combines with the same nouns in its quantifier use as well, whereas heap(s) of can combine with a whole range of nouns when it has the status of quantifier. Nevertheless, it is rare, though certainly not impossible, for the quantifier heaps of to appear with the nouns it typically patterns with when functioning as head, e.g. paper and rubble nouns.

(48) The graphics are very polished, with pitch detail, markings and the like adding heaps of atmosphere.

(49) The "surrogate mum" to princes William and Harry shared heaps of fun with them at a fair yesterday while father Charles was otherwise engaged.

(50) Clearly the superstar was Czar Oak, a late maturing New Zealand-bred stayer with heaps of potential but also a major leg problem.

(51) Certainly heaps of kids are aware of it, carry it out and are brilliant but others seem to have lost the plot.

(52) We received heaps of mango chutney recipes.

Whereas bunch of and pile(s) of seem to radiate a predominantly negative prosody, the examples with heap(s) of seem to point towards positive semantic prosody and express a more positive form of hyperbole.

Even though heap of and heaps of have clearly grammaticalized much further than pile(s) of, heap of in particular displays some metaphorical phenomena similar to those found with pile(s) of:

(53) No wonder I'm so behind on everything. Nothing more romantic than a steaming heap of male potential just beyond your reach.

(54) That deadly, winking snuggling chromium-plated, scent-impregnated, luminous, quivering, giggling fruit-flavoured, mincing, ice-covered heap of mother-love [about Liberace]

Again we could categorize examples like these as 'transitional' or 'vague'. On the one hand they constitute metaphors, literalizing the MN into the head noun. On the other hand, the MN also quantifies N2. The nouns in the of-phrase are often abstract non-stackables, which reinforces a quantifier reading, but 
this is counterbalanced by the presence of premodifiers, encouragining a 'head' interpretation of the $\mathrm{MN}$.

In conclusion to this comparative case study of heap(s) of and pile(s) of, let us return to Lehmann's notion of a grammaticalization cline from which this section set out. We can now attempt to draw an actual scale of grammaticalization with pile of, piles of, heap of and heaps of. A lot of is included to represent the fully grammaticalized predecessor of the MNs looked at in the various case studies. The scale can be visualized as follows:

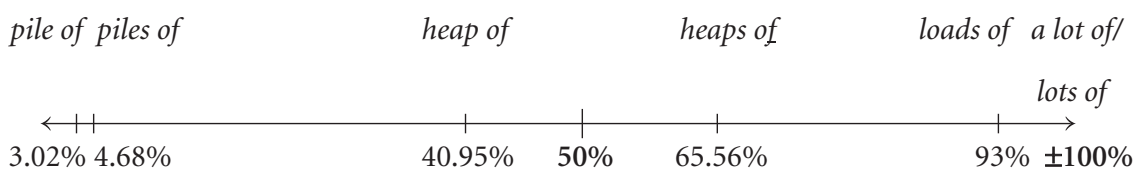

\section{Conclusions}

The corpus studies showed that the assessment of the structural status of MNs in MN-constructions is so complex because of the subtle and often intricate interdependence of the MN's lexical status and the grammatical status. The observed structural fluctuation hence turned out to involve many more dimensions than suggested by theoretical accounts such as Halliday's for instance. Lehmann's parameters for grammaticalization proved essential to impose some order on what appears as intractible material. Grammaticalization, both the diachronic and synchronic interpretation, allows one to show the patterns in empirical data.

Not only is there a synchronic dissimilarity in the extent to which MNs have grammaticalized; each of the various MNs individually displays a layering (cf. Hopper \& Traugott 1993) of lexical head uses and grammatical quantifier uses as well as a considerable number of 'transitional' uses. Some contextualized examples proved to be irreducible "blends" (Bolinger 1961) of quantifier and head status. Our main descriptive research question has thus been confirmed: bunch(es) of, heap(s) of and pile(s) of have developed a quantifier use comparable to that of regular quantifiers. However, they still retain the possibility of appearing as the lexical head noun of a nominal group. It is very important that the existence of the vague category is recognized, if only as an 'in between' stage. It has its communicative usefulness in meeting the language 
user's need for a quantifier as well as procuring expressiveness, e.g. the potential for modifying $\mathrm{MN}$ and $\mathrm{N} 2$.

The MNs thus do constitute an emergent means of quantification (cf. Langacker 1991). The observed structural fluctuation and layering phenomena suggest that they are still very much quantifiers on the move. A certain amount of lexicality is bound to cling to all MN quantifiers to some extent. For 'pile', in particular, such lexical persistence (Hopper \& Traugott 1993) is at present very strong, whereas heaps of, has already developed a systematic quantifier use which is more or less oblivious to its original lexico-semantics. Still, even when MNs have become highly grammaticalized, their lexical semantics can still be exploited, alluded to or revived in various ways, e.g. They employ lorry-loads of insincere flattery. Again the strong interpersonal motivation behind MNs as a means of quantification comes to the fore and should be sufficiently taken into account, as well as the importance of casual, informal registers.

\section{Notes}

1. I would like to thank all people at the 2nd Workshop of the Systemic Functional Research Community (Leuven, 21-24 November 2001) as well as those at ICAME 2002 for their much appreciated comments on earlier versions of this paper. Special thanks are due to Kristin Davidse for carefully revising this paper.

2. These are just two of the many names they are commonly labelled with. Others are "quantifying nouns" in Biber et al. (1999! and "NP-like quantifiers" in Akmajian and Lehrer (1976).

3. All examples marked $\mathrm{CB}$ are extracted from the COBUILD corpus (The Bank of English), which contains over 500 million words, and reproduced with the kind permission of HarperCollins.

4. This concept is alternatively referred to as "semantic attrition", "desemanticization" and “demotivation" (Lehmann 1985: 307).

5. Qualitative adjectives modifying either $\mathrm{MN}$ or $\mathrm{N} 2$, as well as verbal forms, reference items and quantifiers are underlined or otherwise highlighted because they are important indices for 'head' status.

6. At a prior presentation of this paper during the 2 nd workshop of the systemic functional research community (21-24 November 2001) Paul Thibault pointed out that some restrictions are still sensed with regard to the spatial proximity of the N2 referents as well as with regard to their spatial boundedness as in A bunch of rivers.

7. All of these are present in (13) and highlighted by without much method, enthusiastic and very fit and just respectively. 
8. Note also that with examples like a bunch of lies, a bunch of gobbledygook and a bunch of morons the grammaticalized and chunked nature of the $\mathrm{MN}$ is signalled by a "reduction in form" (Bybee 2001: 9) or "phonological attrition" (Lehmann 1985:307) mirroring the coalescence or chunking and desemanticization. In this case the phonetic erosion is rather minimal, reducing full 'of' to a schwa (neutral vowel sound) in more informal spoken contexts.

9. In addition, instead of a vertical dimension, 'heap' incorporates horizontal potential, which is often further lexicalized in the choice of verb ('reduce') or other words in the context.

10. Considering the limited number of corpus examples with pile of used as a quantifier, these examples are near-exhaustive.

\section{References}

Allan, K. (1977). Singularity and Plurality in English Noun Phrases: A Study in Grammar and Pragmatics. Unpublished Ph.D. Dissertation delivered at the University of Edinburgh.

Akmajian, A., \& Lehrer, A. (1976). NP-like quantifiers and the problem of determining the head of an NP. Linguistic Analysis, 2, 395-413.

Biber, D., Johansson, S., \& Leech, G. (1999). Longman Grammar of Spoken and Written English. London: Longman.

Bolinger, D. L. (1961). Syntactic blends and other matters. Language, 37, 366-381.

Brems, L. (2001). From Head to Quantifier: Grammaticalization and delexicalization in Measure Noun constructions. Unpublished MA thesis. University of Leuven: Department of Linguistics.

Brown, L. (Ed.) (1993). The New Shorter Oxford English Dictionary on Historical Principles. Oxford: Clarendon Press.

Bublitz, W. (1996). Semantic prosody and cohesive company: 'somewhat predictable'. Leuvense Bijdragen, 85, 1-32.

Bybee, J. (2001). Cognitive processes in grammaticalization. To appear in Micheal Tomasello (Ed.), The New Psychology of Language, Vol. 2. New Jersey: Lawrence Erlbaum.

Davidse , K. (2001). Postdeterminers: their secondary identifying and quantifying functions. Preprint K. U. Leuven, Department of Linguistics.

Fischer, O. (1999). Grammaticalization: Unidirectional, nonreversible? The case of to before the infinitive in English. Views, 7, 5-24.

Geeraerts, D. (1993). Vagueness's puzzles, polysemy's vagaries. Cognitive Linguistics, 4, 223 272.

Halliday, M. A. K. (1985). An Introduction to Functional Grammar. London: Arnold.

Halliday, M. A. K., \& Z. James (1993). A quantitative study of polarity and primary tense in the English finite clause. In J. Sinclair, M. Hoey, \& G. Fox (Eds.), Techniques of Description. Spoken and written discourse (pp. 32-66). London: Routledge.

Halliday, M. A. K. (1994). An Introduction to Functional Grammar. 2nd edition. London: Arnold 
Haspelmath, M. (1989). From purposive to infintive - A universal path of grammaticalization. Folia Linguistica Historica, 10, 287-310.

Hopper, P. (1991). On some principles of grammaticization. In Elizabeth Traugott \& Bernd Heine (Eds.), Approaches to Grammaticalization, Vol. 1 (pp. 17-35). Amsterdam: John Benjamins.

Hopper, P., \& E. Traugott (1993). Grammaticalization. Cambridge: Cambridge.

Jespersen, O. (1970). A Modern English Grammar on Historical Principles (7 Vols.). London: Allen \& Unwin; Copenhagen: Enjar Minksgaard.

Kruisinga, E. (1925). A Handbook of Present-day English, 7th edition. Utrecht: Kemink en Zoon.

Kurylowicz, J. (1965). The Evolution of Grammatical Categrories. Diogenes, 51, 55-71.

Kurtböke, P. (2001). YAP- and OL- as delexical nominalising devices in diaspora Turkish. Paper delivered at the University of Leuven, March 15.

Langacker, R. W. (1991). Foundations of Cognitive Grammar. Volume 2: Descriptive Application. Stanford: Stanford University Press.

Lehmann, C. (1985). Grammaticalization: Synchronic variation and diachronic change. Lingua e Stile, 20, 303-318.

Lehrer, A. (1986). English classifier constructions. Lingua, 66, 109-148.

Quirk, R., Greenbaum, S., Leech, G., \& J. Svartvik. (1972). A grammar of Contemporary English. London \& New York: Longman.

Quirk, R., Greenbaum, S., Leech, G., \& J. Svartvik. (1985). A comprehensive Grammar of the English Language. London \& New York: Longman.

Sinclair, J. (1992). Corpus, concordance, collocation. Oxford: University Press.

Sinclair, J. et al. (1997). Collins Cobuild English Grammar. London: HarperCollins Publishers.

Thompson, D. (Ed.) (1995). The Concise Oxford Dictionary of Current English, ninth edition. Oxford: Clarendon Press.

Traugott, E. (1988). Pragmatic strenghtening and grammaticalization. Proceedings of the 14th Annual Meeting of the Berkeley Linguistics Society (pp. 406-416).

Vandenbroucke, K. (2001). A bunch of / a load of: process of grammaticalisation. unpublished paper. Linguistic department, KULeuven. 
Copyright of International Journal of Corpus Linguistics is the property of John Benjamins Publishing $\mathrm{Co}$. and its content may not be copied or emailed to multiple sites or posted to a listserv without the copyright holder's express written permission. However, users may print, download, or email articles for individual use. 